\title{
Axons Do Not Necessarily Compete for Targets ${ }^{a}$
}

\author{
BRUCE OAKLEY \\ Department of Biology \\ Neuroscience Laboratory Building \\ University of Michigan \\ Ann Arbor, Michigan 48109
}

Competition exists if $\mathbf{A}$ receives less because of the presence of $\mathbf{B}$. Synergism occurs when the effects of A and B acting together exceed the sum of their separate effects. It is in vogue to assume that interactions between axons are competitive; however, axons might be expected to interact synergistically in instances where they exert trophic effects upon their targets. Possibilities include trophic effects upon glial cells, promotion of the outgrowth of dendrites or dendritic spines, or prevention of cell death in neurons receiving axonal projections. In some of these circumstances, innervation of the target cell by axon $A$ might increase, rather than decrease, the probability of synapse formation by axon $B$.

Our recent observations indicate that taste axons in the rat vallate papilla normally interact in a noncompetitive, synergistic manner to augment the number of taste buds induced during development by more than 150 . The vallate papilla of the rat is normally innervated by the right and left IXth nerves. One IXth nerve alone forms a mean of 228 vallate taste buds.' Two IXth nerves form, not twice 228 , but 610 taste buds. ${ }^{2}$ Thus, more than 150 additional taste buds are added because of synergistic interactions between the right and left IXth nerves.

Taste buds in the vallate papilla are neurally induced during a sensitive period that is maximal from 0 to 10 days postpartum. ${ }^{3}$ After one IXth nerve is removed and the other crushed at three days of age, only 30 of the 610 vallate taste buds eventually develop. However, after both IXth nerves are crushed at three days, 144 vallate taste buds develop. Thus, in these experiments with crushed IXth nerves, the synergism among axons is even greater, as doubling the nerve supply (two crushed nerves) nearly quintuples the number of taste buds. The surviving axons of one crushed nerve (mean $=835$ myelinated axons vs. 1897 in a normal nerve ${ }^{1}$ ) may be so dispersed in the papilla that the innervation density is insufficient to form more than a few (30) taste buds. The addition of a second IXth nerve may increase the innervation density above the threshold level necessary to form taste buds at many sites in the gustatory epithelium. This implies that the number of bilaterally innervated taste buds should increase according to the number of axons in the right and left IXth nerves. This inference is supported by a stochastic analysis that predicted to a first approximation the number of bilaterally innervated taste buds, given the number of axons in the right and left IXth nerves after nerve crush.'

\footnotetext{
a This research was supported in part by National Institutes of Health Grant NS-07072.
} 
During development the IXth nerve forms $75 \%$ and the chorda tympani about $30 \%$ of the 121 foliate taste buds. Since the total is close to $100 \%$, there is no evidence that some taste buds require dual innervation by both the IXth and chorda tympani nerves for development. However, in adults the IXth nerve will maintain all 121 foliate taste buds, including all of those formed by the chorda tympani. Hence, sometime before 90 days postpartum, the IXth nerve axons must provide enough innervation to maintain the chorda tympani pool of taste buds.

Why does synergism occur in the vallate papilla between the right and left IXth nerve but is not evident in the foliate papilla between the chorda tympani and IXth nerves? The chorda tympani seems to form its own pool of taste buds. Indeed, the chorda tympani induces about 35 taste buds whether the IXth nerve is present or absent during development.

Underlying the interactions between two nerves during taste bud induction are three possible models of dual innervation in which the innervation density might be: (a) so high that either nerve could have formed the given taste bud (logical "or"), (b) so low that both nerves are required (logical "and"), or (c) great enough for one nerve to form the taste bud, but not the other nerve. Model $b$ is present in the vallate papilla and model $c$ may be present in the foliate papilla.

The existence of innervation of taste papillae by two nerves has provided a convenient way to examine interactions among taste axons. Examples of synergistic, noncompetitive interactions among axons have been established for bilaterally induced taste buds in the vallate papilla of the rat. Rather than assuming that competition is the rule of interaction among axons, one should consider the possibility of synergism in those situations where axons have neurotrophic effects upon neuronal or nonneuronal targets.

\section{REFERENCES}

1. Hosley, M. A., S. E. Hughes \& B. OAKLey. 1987. Neural induction of taste buds. J. Comp. Neurol. 260: 224-232.

2. Hosley, M. A. \& B. OAKLey. 1987. Postnatal development of the vallate papilla and taste buds in rats. Anat. Rec. 218: 216-222.

3. Hosley, M. A., S. E. Hughes, L. L. Morton \& B. OAKLey. 1987. A sensitive period for the neural induction of taste buds. J. Neurosci. 7: 2075-2080. 